\title{
Chitin \& Lignin: Turning Food Waste into Cosmeceuticals
}

\section{Pierfrancesco Morganti ${ }^{1 *}$, Hong-Duo Chen², Xin-Hua Gao ${ }^{3}$, Gianluca Morganti ${ }^{4}$ and Davide Febo ${ }^{5}$}

${ }^{1}$ Professor of skin pharmacology, Dermatol Unit, Campania University, Italy

2Professor of Immuno Dermatology, No.1 Hospital of China Medical University, China

${ }^{3}$ Professor and Head depart Dermatology, No 1 Hospital of China Medical University, China

${ }^{4}$ ISCD R\&D Center, Rome, Italy

${ }^{5}$ Atertek, R\&D Center, Pescara, Italy

*Corresponding author: Pierfrancesco Morganti, Professor of skin pharmacology, Dermatol Unit, Campania University, Italy, Tel: 390815666833; E-mail: pierfrancesco.morganti@iscd.it

Received: 14 Nov, 2018 | Accepted: 11 Dec, 2018 | Published: 21 Dec, 2018

Citation: Morganti P, Chen HD, Gao XH, Morganti G, Febo D (2018) Chitin \& Lignin: Turning Food Waste into Cosmeceuticals. J Clin Cosmet Dermatol 3(1): dx.doi.org/10.16966/2576-2826.135

Copyright: (C) 2018 Morganti P, et al. This is an open-access article distributed under the terms of the Creative Commons Attribution License, which permits unrestricted use, distribution, and reproduction in any medium, provided the original author and source are credited.

\section{Abstract}

The $\sim 3$ billion tons/year of worldwide food waste represents a great environmental problem to be positively solved. Thus, it may be used as an interesting raw material to be transformed in useful biodegradable goods. In the same way an agricultural correct waste management can prevent further environmental damage. For both these waste it is possible to obtain chitin and lignin respectively to be used for producing biodegradable tissues to make, for example, baby diapers, beauty masks and advanced medications, according to the EU research project PolyBioSkin. This paper reports some results obtained by the use of both nano-chitin and nano-lignin.

Keywords: Chitin Nanofibrils; Nano-lignin; Biopolymers; Food waste; Agricultural waste; Regenerative medicine; Wound care; Baby diapers

\section{Introduction}

\section{Biocompatible tissues for skin regeneration}

Cosmetic Dermatology has an everyday need of biocompatible tissues for the skin regeneration of diseased or aged skin. These special tissues are generally, used as advanced medications to speed up treatment and recovery of wounds and skin burns, or as cosmetic facial masks for soothing the great problem of skin aging and photo-aging, trying to slowdown the appearance of fine lines and wrinkling.

Looking to a market report, it is to underline that the global regenerative medicine sector (Figure 1) [1] registered a turnover of US\$ 18.9 billion in 2016 with an estimated growth to over 53.7 billion by 2021 and a Compound Annual Growth Rate (CARG )of 24\%, $\sim 10 \%$ of which is represented by the engineered regeneration tissues.

This CAGR is due to the population growth that will range 9.7 billion in 2050 (Figure 2) [2] with an increased aging numbered 962 million in 2017 [3]; the growing demand and use for advanced medications i.e., for example, innovative non-woven tissues [4]; and the increased investments in $\mathrm{R} \& \mathrm{D}$.

On the other hand, the global cosmetic market was US $\$ 460$ billion in 2014, being estimated to reach US\$ 675 billion by 2020 [5,6] with a global mean CARG of about $5 \%$ and a continuing and increasing requests for innovative natural products (Figure 3).
Thus the necessity to develop innovative and bio-based/organic cosmetics which has been estimated to have an interesting CARG of $9.6 \%$ in 2018 compared to 2017 , according to the actual consumer preferences.

In this market, the Facial tissue masks, dominated from China and the Asia Pacific Countries (APAC), has been estimated US\$ 1.6 billion with an average annual growth of nearly $40 \%$ ! [6]. These masks, which actually represent a niche of the global cosmetic market, are marketed by claims that, enhancing effectiveness and safeness of the active ingredients used, transfer and confer their activities to the final product.

Particularly, they are described to possess distinct and characteristic benefits for the aged skin, such as, for example, slowing down wrinkling and aged spots. However, it is to underline that the used claims are too often based on the ingredients activity only, while, rarely they show the effectiveness of the final product by in vitro and in vivo studies, realized according to the scientific international rules. For these reasons and in my opinion, Chinese Dermatologists should show more focus on this category of products.

These innovative cosmetics, in fact, positioned at the borderline between the medical and holistic effectiveness have to be studied and controlled first of all by the medical community, and particularly by Dermatologists and Plastic surgeons, for the deep knowledge they have on both structure of skin, its appendages, and mucous membranes. 


\section{GLOBAL REGENERATIVE MEDICINE MARKET}



Figure 1: Global regenerative medicine market.

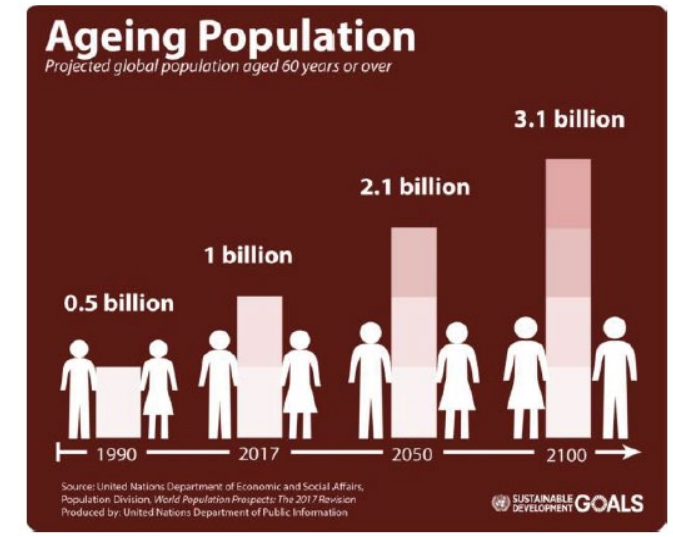

Figure 2: Increased global aging population growth projected to 2100.

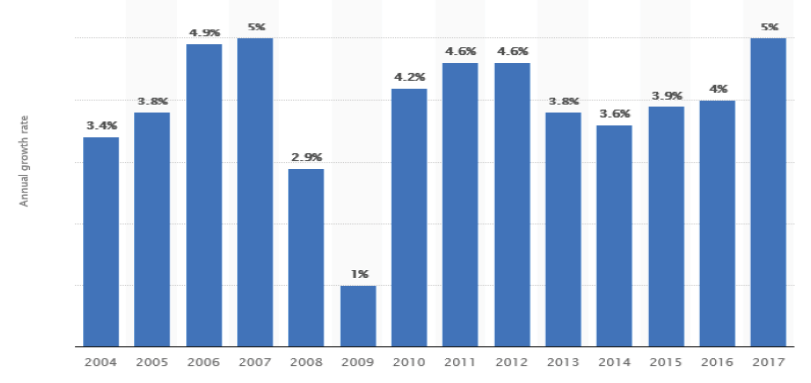

Figure 3: Annual growth of the global cosmetics market from 2004 to 2017 (source: STATISTA GmbH, Hamburg, Germany).

\section{Advanced medication and innovative cosmetics}

While on the one hand, new advanced medications and tools promising to treat complicated degenerative disorders affecting patients are continually appearing on the market, on the other hand cosmetic products-effective for treating the skin aging processes seem to be the solution claimed for all the consumers.

However an innovative manufacture of these products may be obtained by the support of specialized bio-nanotechnologies, identified in $\mathrm{EU}$ as one of the key-enabling technologies driving innovation [7]. Innovation, particularly important for a future growth, involves the creation and diffusion of new products, processes and methods, providing the foundation of new business and new jobs, characterized for a specific productivity increase [8]. This is why in this historic period innovative economies, such as the Chinese ones are more productive more resilient, more adaptable to change and better able to support higher living standards [9].

Thus, according to Euromonitor International, the beauty and personal care market of Asia-Pacific region (APAC) is set to grow by more than 30\% over the next four years, reaching US\$ 192 billion by $2021[10]$.

Indonesia by $50 \%$ and China by $46 \%$ are the APAC countries expected to experience the most growth, followed by Malaysia and Vietnam which are forecast to grow by $41 \%$ and $39 \%$ respectively.

On the other hand, as previously reported, the advanced woundcare segment is the fastest area with a double-digit growth of $10 \%$ per year, driven worldwide by the aging population, the rise in the incidence of diabetes and by a steady advancement in technology and products, considered more clinically efficient and more cost-effective, than their conventional counterparts $[4,11]$

Unfortunately according to the US Health Research Institute [11], the global medical growth rate expected in 2015 was modest, compared to the double-digit annual increase seen throughout the late 1990 s and early 2000s.

On the other hand, the consumer global emerging economies, varying climatic conditions, changing lifestyles, rise in male grooming, and increased demand for natural or bio-based products, are all encouraging the growth of the cosmetic market.

However, the challenge is to continue to control spending, even in the face of countervailing winds, such as innovations, improved consumer confidence, and an aging society that requires more medical care and esthetic services.

In conclusion, innovative tissues made by natural and biodegradable fibers, obtained from agricultural and industrial by-products, seem to have an important market in both the Dermatological and Cosmetic fields, if the industry will be able to market these products in a great quantity and at a low cost.

Among the discharged materials, chitin and lignin seem to be ideal ingredients because biodegradable, skin-friendly, environmentallyfriendly, and obtainable by technologies funded on the use of fishery's by-products and agricultural biomass respectively [12].

\section{Bio-polymers from food and agricultural waste}

Both Chitin Nano fibrils (CN) and Nano-Lignin (LG), as natural bio-polymers, could be extensively used in cosmetic dermatology to produce biocompatible tissues at low cost. The two polymers, in fact, may be obtained from natural and waste materials, ranging about 300 billion tons every year, $\sim 20 \%$ of which are used to produce energy only $[13,14]$. Just as an example the chitin turnover seems to be about 10 giga tons per year and if we do not use this waste material, it is estimated that we would be seat on a mountain of it within 10-100 years!

However, it is interesting to underline that both chitin and lignin may be extracted from food waste obtained from the industrial processes of crustaceans and sugarcane respectively. The use of these by-products could surely represent a source of social, environmental and economic benefits. For these reasons, the increasing interest to solve this problem became a necessity of our society. 
According to FAO evaluations [15], each year one third of all food produced for human consumption in the world ( $\sim 1.3$ billion tons) is lost or wasted, impacting on the environment by a great carbon footprint.

On the other hand, being 1 billion people chronically malnourished, it will be necessary to increase food production by $50 \%$ to $100 \%$ by 2050, not only for the growing population and the wasted food, but also because the same population is shifting towards more meat-and dairy-intensive diets [15].

Thus, on the one hand the Planet is organized by balanced systems of fauna \& flora, able to create perfect scale-economies (Figure 4 Terrestrial ecosystem).

On the other hand we humans waste away this ecological and biophysical organization, through "the renewable resources we consume for food and fuel, the land we build on, and the forest necessary to absorb our carbon emissions" [16]. The actual agricultural systems, in fact, are concurrently degrading land, water and climate on a global scale by the emission of $\mathrm{CO}_{2}$ and $\mathrm{CH}_{4}$, being the main drive of the biodiversity loss and the major contribution to climate change and pollution [15]. Instead of expanding croplands to meet the needs of the worldwide growing population, it could be better, therefore, to change diet and way of living, producing biofuel to reduce Greenhouse Gas (GHGs) emissions and maintaining vegetation and soil at their natural conditions (Figure 5) [16].

However, the most significant benefits of proper bio-waste management seem to be the production of good quality composts and plant elicitors, innovative consumer-goods, smart tissues, and biogas, contributing to enhance both soil quality and resources efficiency, for obtaining an higher level of self-sufficiency energy and a better way of living [17].

Therefore, a more intensive and proper management of industrial and agricultural by-products could contribute to ameliorate the environmental condition. Drastically reducing both GHGs emissions and food scarcity.

\section{Chitin and lignin: from cell defensive-polymers to healthy tissues}

Among the variety of polysaccharides, recovered in great quantity as waste material, the natural polymers chitin and lignin could be utilized to produce innovative non-woven tissues for medical and cosmetic use, according also to a new EU research project named PolyBio-Skin $[18,19]$. They, made by bio-based industrial processes and biologically-derived waste materials, are expected to be much more sustainable and characterized for their low emission of $\mathrm{CO}_{2}$.

These new non-woven tissues were realized from our group by both electrospinning and casting technologies and the use of $\mathrm{CN}$ and LG polymeric fibers, binding different active ingredients [20]. Additionally these fibers, organized as tissues having a structure similar to the natural Extracellular Matrix (ECM) (Figure 6), were able to facilitate the normal cells functions. The CN-LG complex, in fact, has shown to normalize in a short time the skin microbiota function, regulating the cytokines cascade and the synthesis of both lipid lamellae and collagen [20].

Thus, by the use of these bio-nano-polymers, it seems possible to produce at low cost advanced medical tissues, characterized for their anti-inflammatory, immune-modulatory, and skin repair effectiveness $[20,21]$, as well as to made innovative cosmetic tissues with protective, moisturizing and anti-aging activity [22].

In fact, these chitin-lignin scaffolds, used as carriers for their physicochemical and biological effectiveness, have the capacity to load the selected active ingredients, releasing them at the right dose, right time and right skin layer [20-24]. At this purpose, it is interesting to underline that both chitin and lignin are natural, organic macromolecules produced and used to protect from the pathogen aggressions the cell wall of both plant and animals [25,26].

Lignin, as well as chitin, possesses multiple functional groups that can form inter-and-intra molecular hydrogen bonding, which affects the compatibility with host matrices [26,27]. In fact like crustaceans, insects and mammals, also plants possess physical barriers that protect them from the entry of pathogenic microorganisms. At this purpose, an important component of the innermost layer of cell wall barrier is lignin for the plant and chitin for crustaceans.

\section{Lignin}

Lignin is made of monomers hard to degrade that, bonding to each other randomly and having the possibility to face different polymeric structures every time, render difficult the entry of pathogens [28].



a)

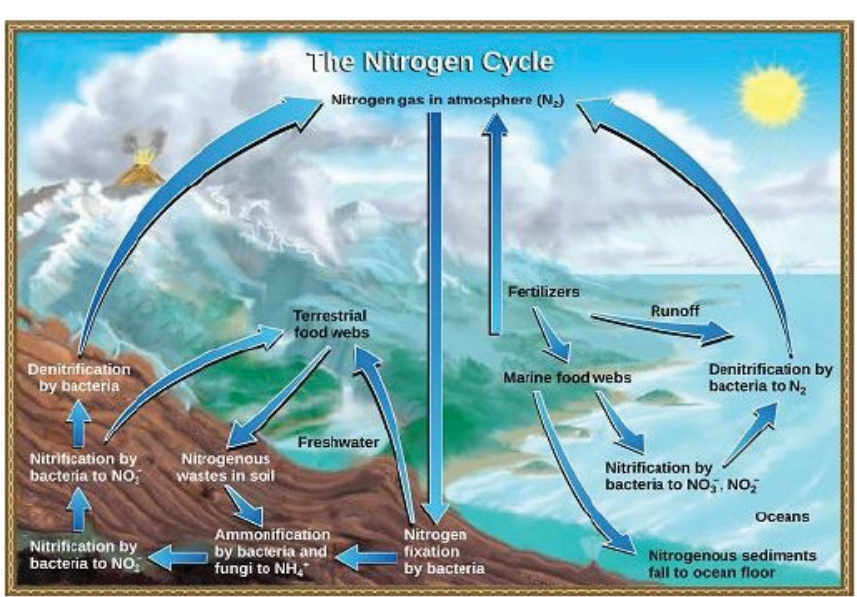

b)

Figure 4: (a) Carbon Cycle. (b) The Nitrogen Cycle. 
When pathogens try to overcome the cell wall, plant recognizes them by a specialized sensory system which similarly to human's antibodies, provides a dynamic interface barrier with the contemporary production of protective molecules [28]. Once the pathogens have been recognized, signal molecules are released to activate the so called inducible immune system and prevent the infection [29].

\section{Chitin}

Similarly, nano-chitin stops pathogen entry and infection phenomena, inducing cytokines and chemokines production $[21,30]$. In any way, this defensive role is complex and size-dependent and it is activated by innate and adaptive immune responses.

Each different chitin size binds to different receptors and activates different intracellular signaling pathways, acting as pro-inflammatory or anti-inflammatory polymer: large chitin polymers are biologically inert, intermediates sized $(40-70 \mu \mathrm{m})$ trigger inflammation, while smaller ones $(<40 \mu \mathrm{m})$ stimulate the macrophage IL-10 production to an anti-inflammatory response $[31,32]$. This probably the reason of the effectiveness shown by chitin nanofibrils (mean size $120 \times 7 \times 5 \mathrm{~nm}$ ) to repair wounded/burned skin and slow down the aging processes [20-22,30].

Chitin therefore, organized by chains assembled in the form of microfibrils (Figure 7) [33], represents a vital defensive structure for insects and crustaceans for the mechanical function performed by the respective cuticle and exoskeleton [34]. Moreover, as previously reported, this natural polymer acts also as immune compound, contributing to slow down the skin inflammatory cascade, and accelerating the tissue repairing processes, always depending by its molecular size [31,32].

\section{Chitin and lignin as carriers}

These the reasons of the increasingly interest for both chitin and lignin as biodegradable molecules to be used as carrier and active ingredients, being also easily metabolized from the human's microbiota enzymes [30,35]. Chitin, in fact, metabolized to glucosamine, acetylglucosamine and glucose, is used as raw material and energy for the human cells respectively, while lignin could reinforce the cell redox system, thanks to the antioxidant property of the polyphenol units, composing its molecular structure.

However, while our fundamental understanding of the human microbiota and biological processes is evolving day by day, it is necessary to find new approaches for a better knowledge and utilization of the body's immune system and the natural microbial colonies, essential to neutralize both pathogen microorganisms and viral infections.

In fact, the new worldwide increasing approaches to the treatment of many diseases include the activation of individual's personal microbiota and the natural immune protection for fighting the new incoming bacteria and try to solve the battle against the antibiotic resistance [35].

These results, in my opinion, could be obtained enabling a new era of clinical care through the use of innovative research studies and technologies, as well as through policies that empower patients, scientists, and producers to work all together, toward the development of individualized personal care products, by the so called Precision Medicine (PM) [30,36] and Traditional Chinese Medicine (TCM) [36,37]. According to TCM, PM has the same aspiration to diagnose and cure illness on an individual basis and in a targeted way, without the harmful side-effects of mass medicine. Thus the necessity for giving a boost to biology and biotechnology to promote wellbeing for all, at all ages, and in every country.

This the aim of these innovative non-woven tissues able to load, carry, and release different active ingredients (entrapped into micronano block polymeric particles) at skin level, without the use of emulsifiers, preservatives, fragrances, colors and other chemicals, necessary for producing solutions, gels, and emulsions, according to the actual cosmetic technology.

So doing, a new era in Cosmetic Dermatology could be open.

\section{Effectiveness and safeness of nanochin-nanolignin tissues}

The skin repairing activity shown from the chitin-tissue is probably due to the same structure of the natural ECM, being able to facilitate the global cell reproduction and survival. Moreover, as previously reported, it is catabolized by the human enzymes to glucosamine, acetyl-glucosamine and glucose, used as active nutrient compounds and/or cell energy [39].

On the other hand the effectiveness of lignin has probably due to the antioxidant property of monomers, characterizing its macromolecule [40].

Thus, from many results obtained from our group during 10 years of research, it has been shown that chitin, produced as Chitin Nanofibrils $(\mathrm{CN})$, has the ability to increase the production of defending (Figure 8 ) and modulate the synthesis of metalloproteinase 2 and 9 (Figure 9) [22].

A faster cicatrizing process without formation of hypertrophic scars or keloids is therefore favored [41], because of the more regularized production and disposition of collagen fibers at skin level (Figure 10) [42], accompanied by a probable fine regulation of the skin microbiota equilibrium between saprophyte and pathogenic microorganisms.

At this purpose it is interesting to underline that the skin repairing and remodeling activities has been modulated by the unsuspected antimicrobial clinical effectiveness, shown from a gel of $\mathrm{CN}$ used to repair important wounds in an African hospital lacking of antibiotics (Figure 11).

The same clinical effectiveness has been verified by non-woven tissues used to repair skin affected by burns of first and second grade (Figure 12) [43].

Moreover, an increased skin hydration (Figure 13) [44], the reduction in number of wrinkling (Figure 14) and aged spots (Figure 15) [41] was observed by the combined use of nano-chitin complexed with hyaluronic or nano-chitin-lignin, embedded into emulsions or beauty masks respectively [44-46].

Finally, an anti-pollution effectiveness has also been recently evidenced from our group by an in progress study (Figure 16).

This further activity seems to be connected to the possibility these sugar-like chitin/chitosan compounds have shown, because of their capacity to: (a) complex heavy metals and micro/nanoparticles present in the environment nanoparticulate [47]; (b) restore and strengthen the skin barrier structure and function $[43,45]$; (c) reduce the inflammation cascade $[21,48]$; (d) replenish the antioxidant reserves [21,44]; (e) control melanin synthesis and transport [48]; (f) promote collagen and elastin synthesis [44]; (g) protect skin from the harmful UV rays $[50,51]$.

At this purpose, it is to remember that pollution contributes to premature skin aging, exacerbating some pathologies such as acne, atopic dermatitis, psoriasis, and cardiovascular diseases [51,52]. 


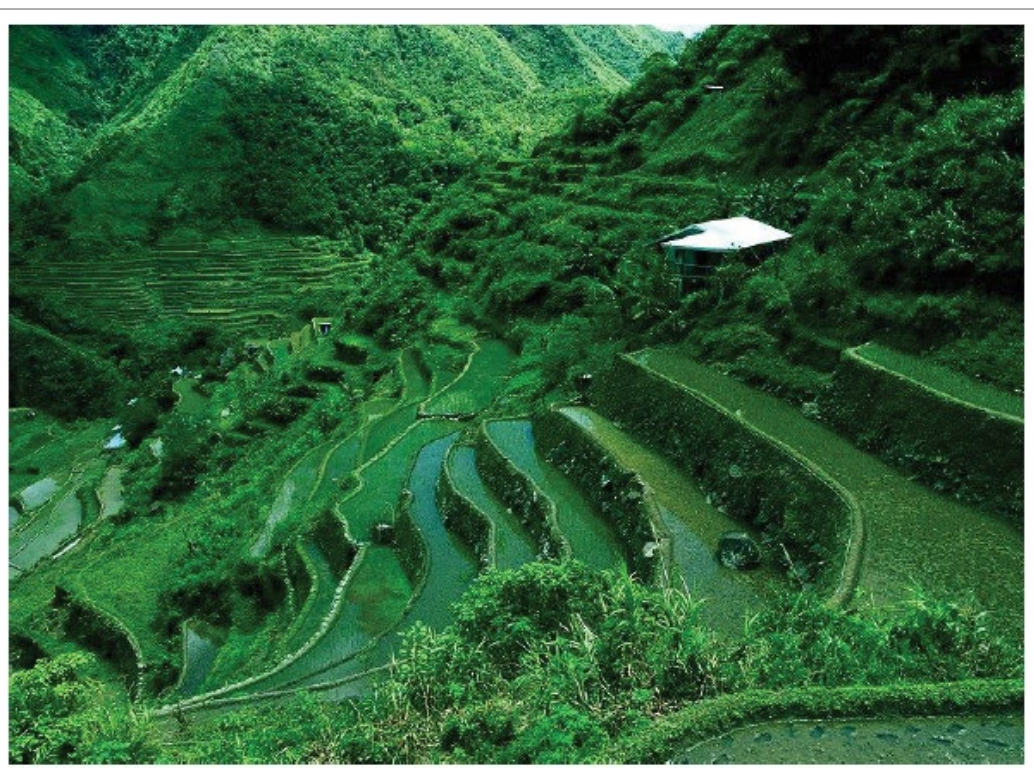

Figure 5: Ecological use of land.

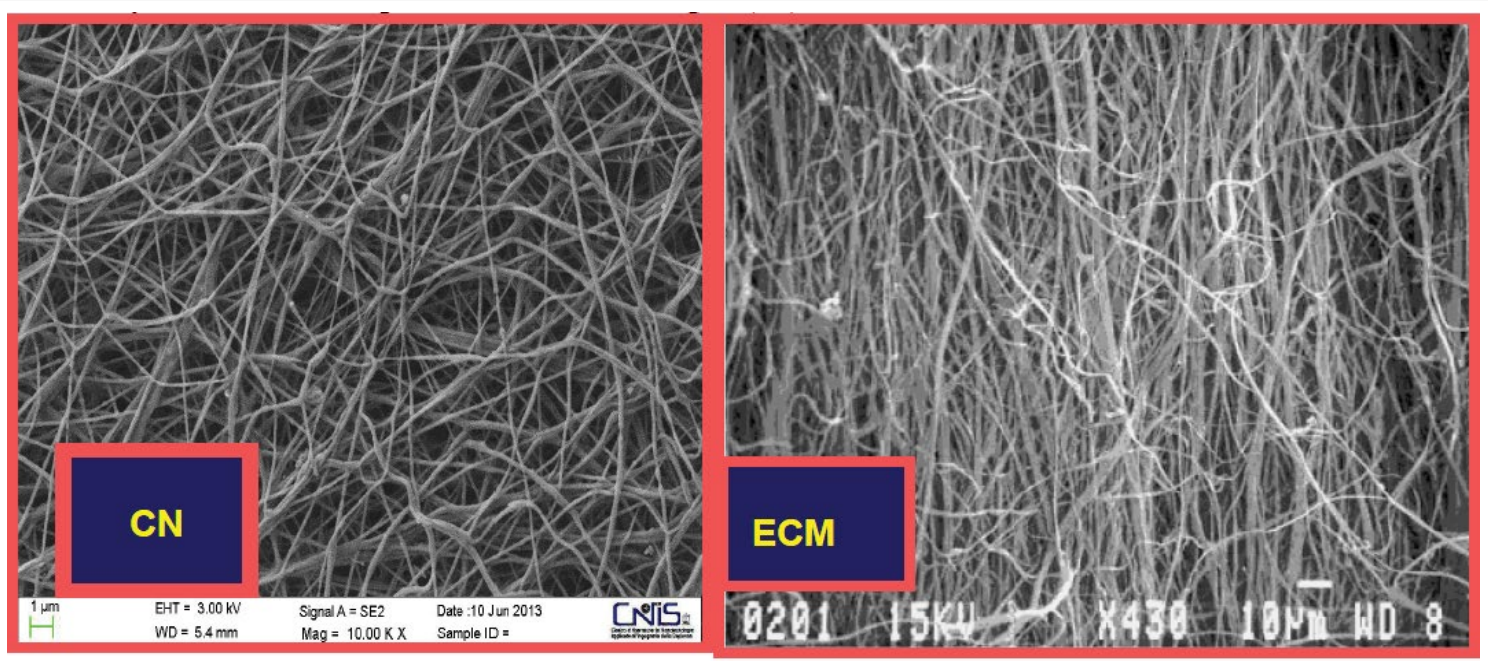

Figure 6: Chitin tissue at SEM (left) compared at natural ECM (right).

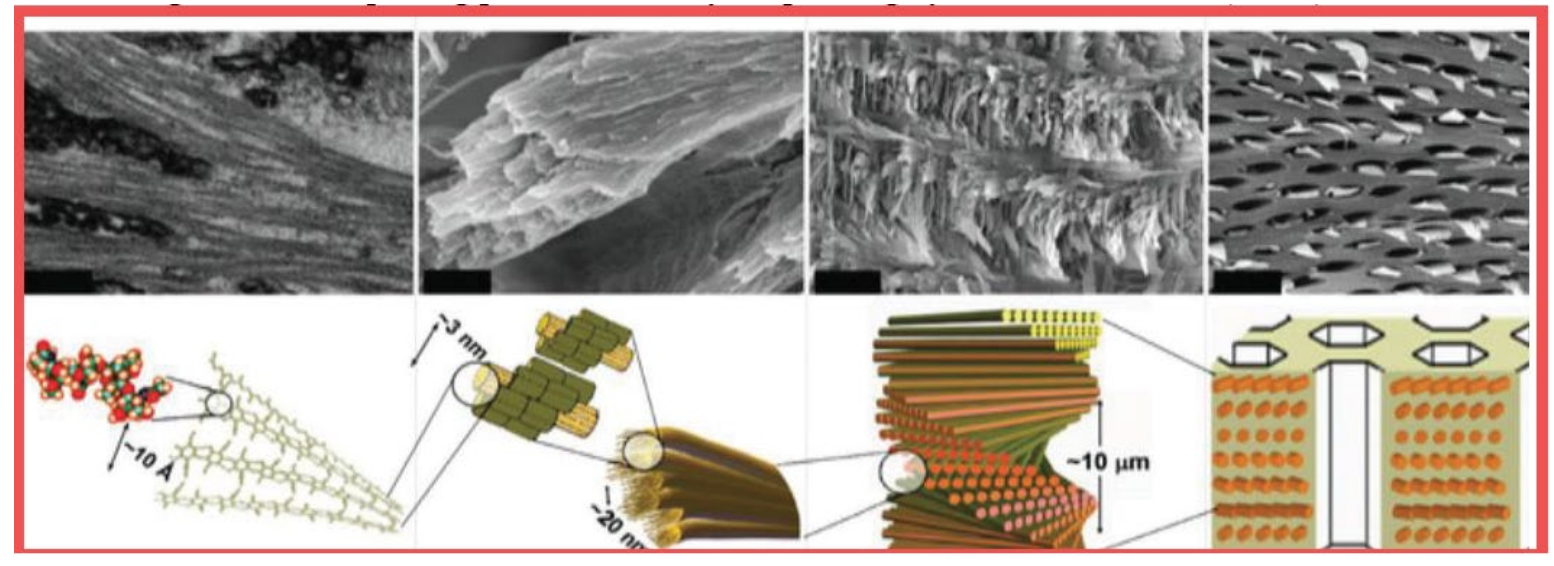

Figure 7: Chitin chains assembled in nanofibrils (by courtesy of Svetoslan et al. [33]). 


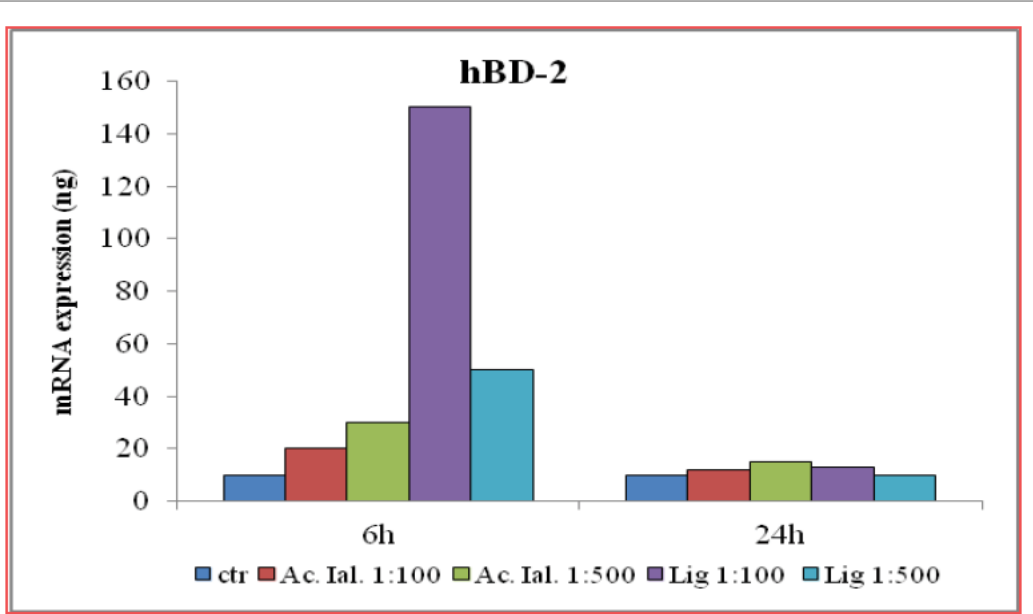

Figure 8: Increase of defensive production from human Keratinocytes treated by chitin nanofibrils.

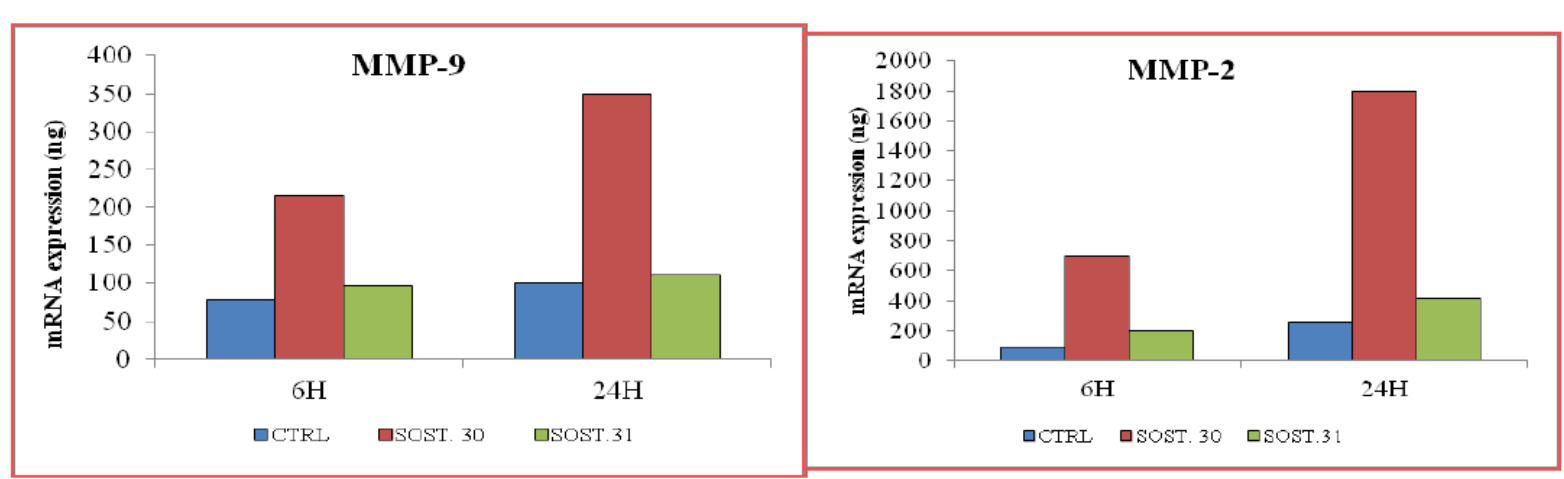

Figure 9: Decrease of metalloproteinases 2 and 9 on human kerstinocytes treated by chitin-nanofibrils.

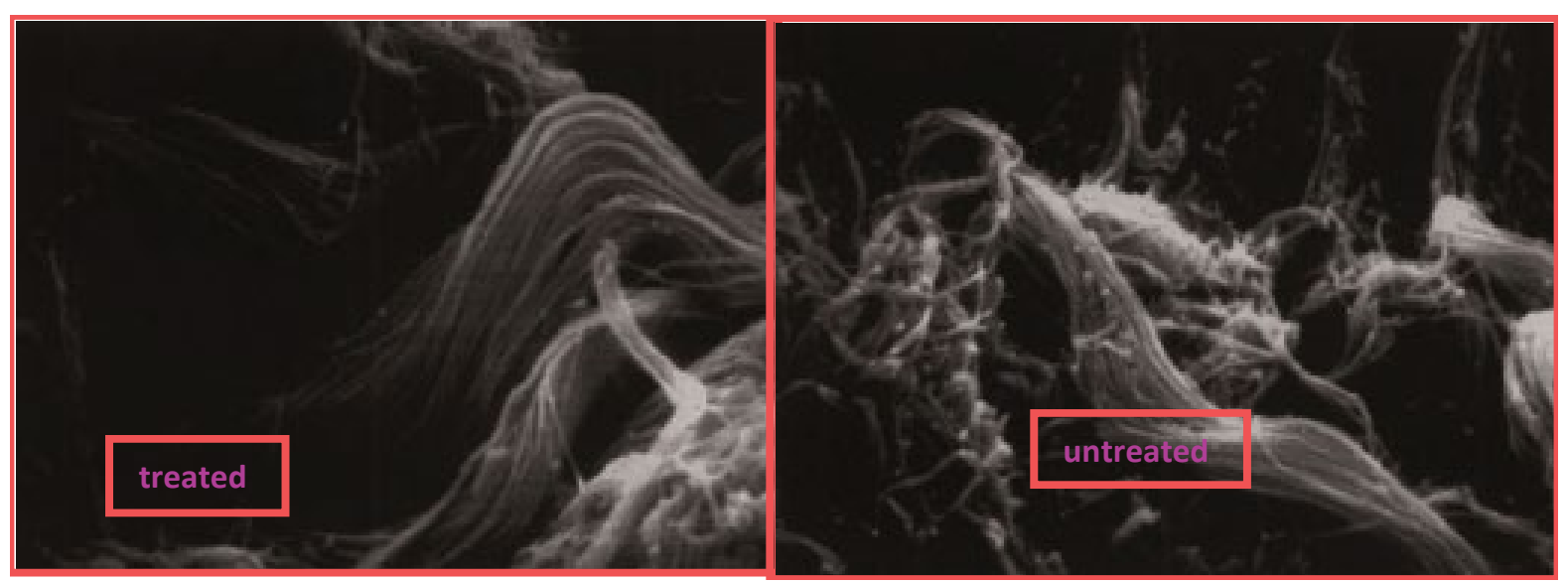

Figure 10: Collagen fibers disposition on skin treated by chitin nanofibrils.

This the reason why many patients and consumers being very concerned about atmospheric nano-particulates, are finding remedies from dermatologists, plastic surgeons and beauticians.

Moreover, it is to remember that, according to WHO, over 3 million people die annually due to pollution while about $90 \%$ live in an area that do not comply with its air quality guidelines [54].

\section{Conclusive Remarks}

The increasing energy request day-by-day together with the necessity to reduce both petrol consume and the global warning are stimulating the growing demand for renewable polymer products such as chitin and lignin, characterized for their low carbon footprint.

Due to their mechanical and immune protective activity, these polymers have shown to be effective against the pathogen aggressions and therefore, ideal candidate to produce non-woven cosmeceuticaltissues for medical and cosmetic use. Moreover, as previously reported 

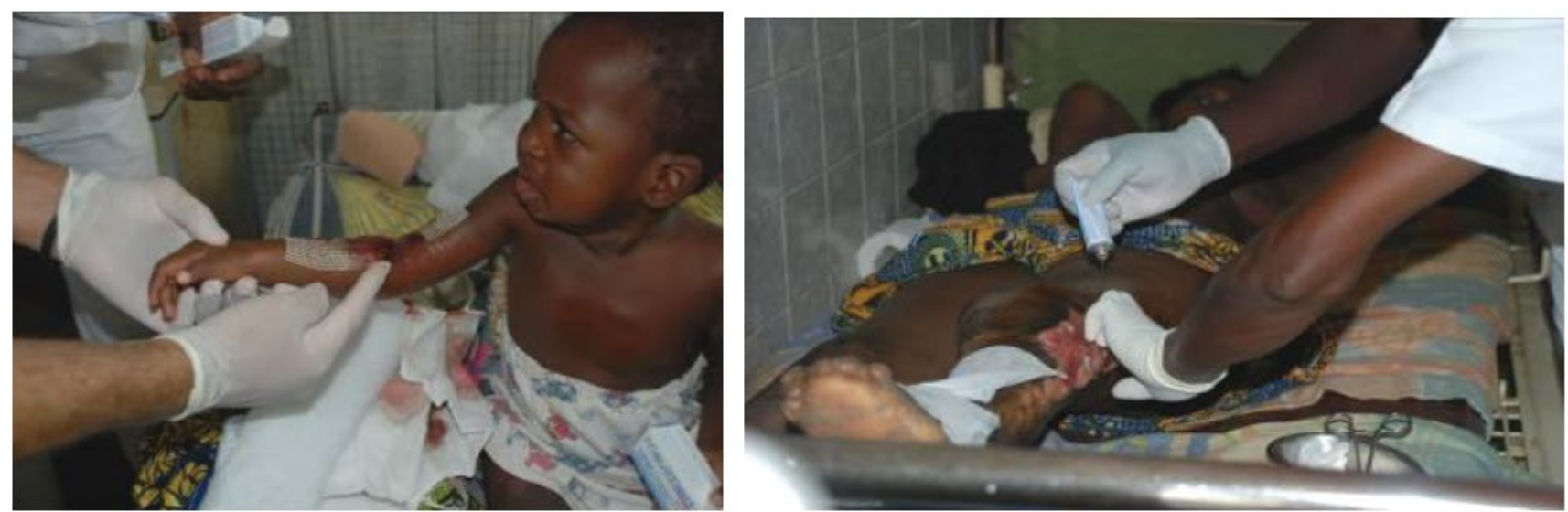

Figure 11: Repairing activity on wounds of African patients treated by a gel of chitin nanofibrils.
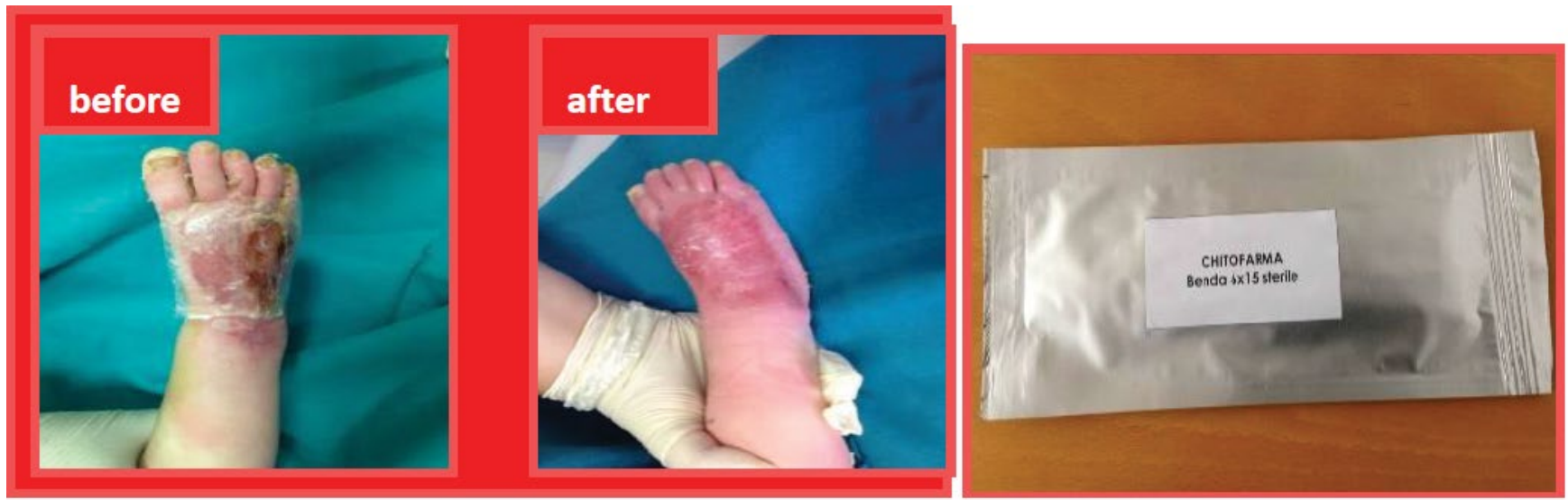

Figure 12: Repairing activity on 2 grade burns of a baby treated by a tissue made by chitin-nanofibrils.

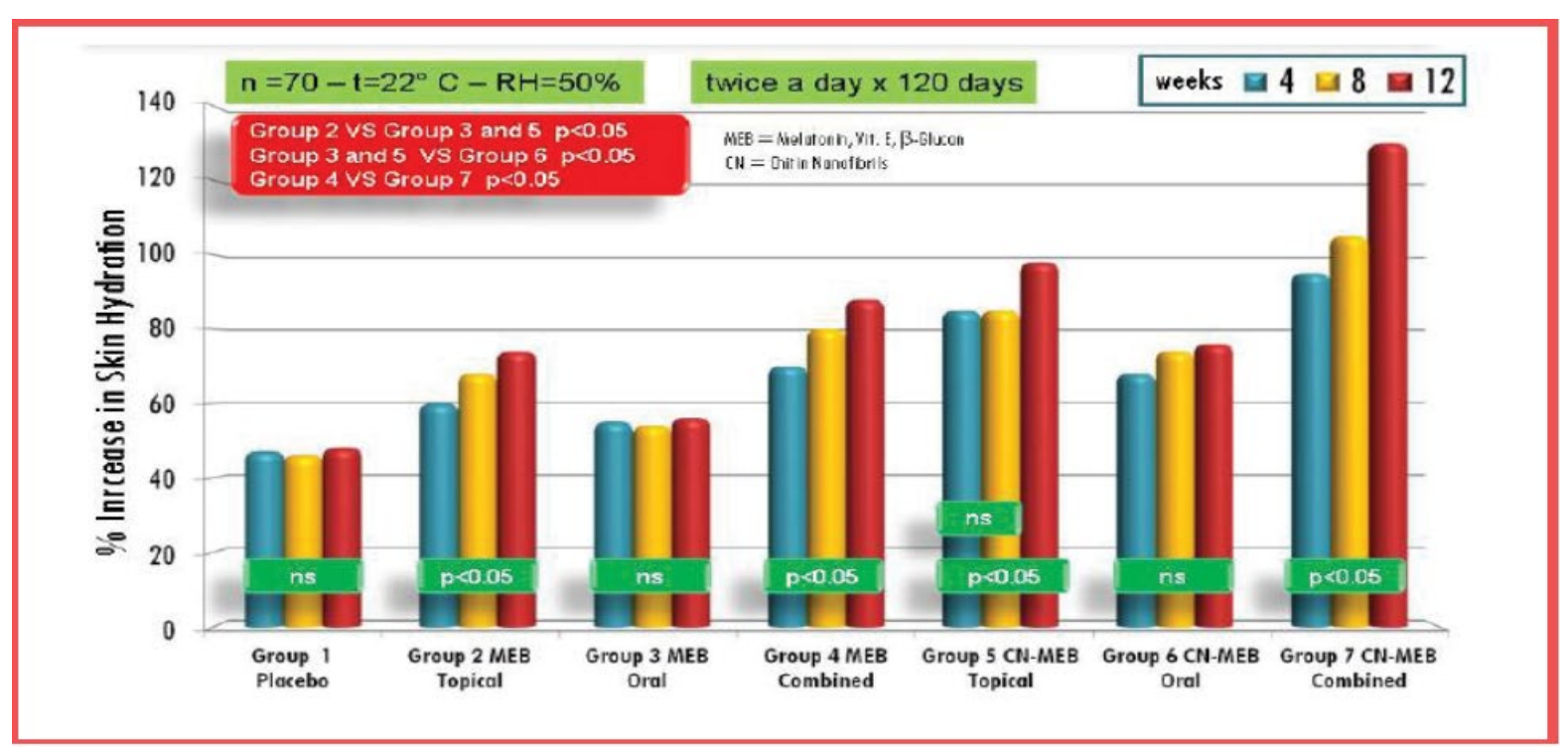

Figure 13: Increased skin hydration of skin treated by an emulsion based on nanochitin-hyaluronan complex. 


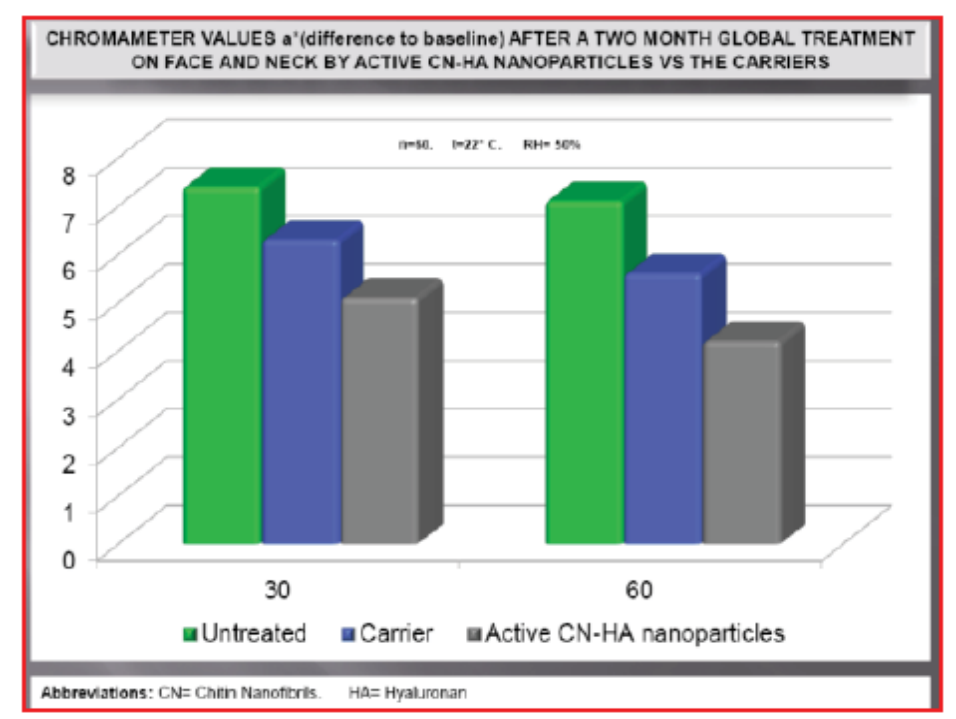

Figure 14: Reduction of fine wrinkling of skin treated by an emulsion based on nanochitin-hyaluronan complex.

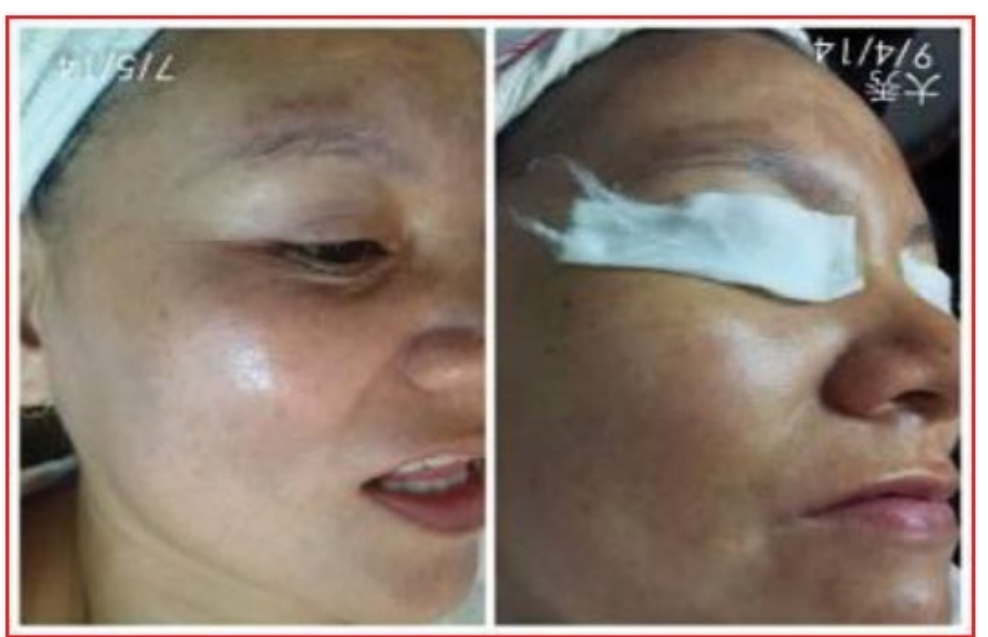

Figure 15: Reduction of black spots of skin treated by an emulsion based on nanochitin-nanolignin complex.

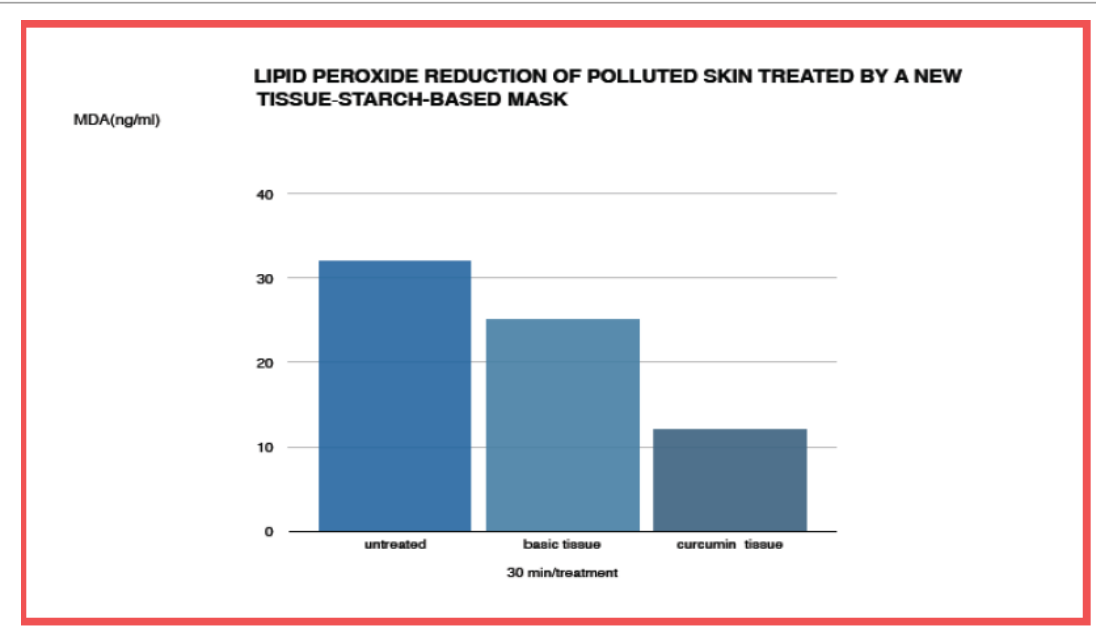

Figure 16: Antipollution activity recovered on skin of urban subjects treated by an emulsion based on nanochitin-nanolignin complex. It was controlled the skin MDA content. 


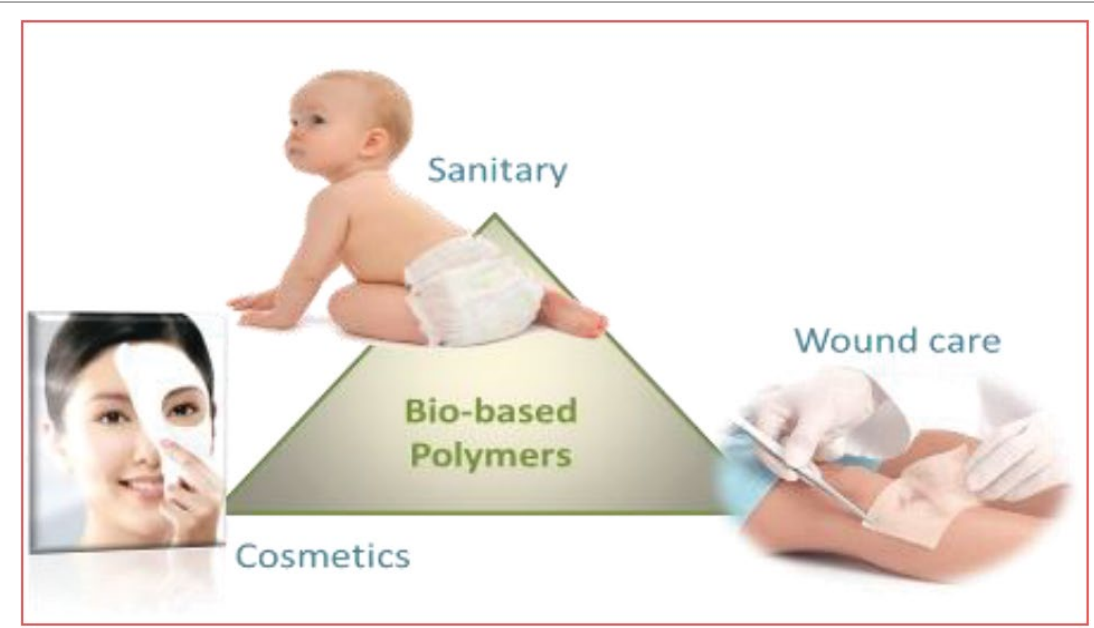

Figure 17: The PolyBioSkin goal.

these polymers are natural compounds obtainable from waste material at low cost and totally biodegradable to nontoxic and cell-friendly molecules.

Additionally, they may be easily produced by both electrospinning and casting technologies, when used at their nano-dimension $[55,56]$. In fact, the obtained non-woven tissues or films, made by the nanostructured chitin and lignin, have shown to have a better availability and an interesting and higher effectiveness and safeness, when used to make beauty masks [44] and advanced medications [43], probably for their high surface area to volume ratio.

In conclusion, the use of chitin nanofibrils and nano-lignin to produce non-woven tissues or emulsions could represent a mean for introducing biodegradable and innovative products in both the medical and cosmetic market. These smart non-woven cosmeceutical-tissues may be used not only to produce advanced medications [20,30,57] and beauty masks $[20,43]$, but also innovative biodegradable fabrics for the baby, women and elderly diapers reducing contemporary the actual unsustainable waste. This is the aim of our research group and the goal of the in progress EU PolyBioSkin project also (Figure 17) [58].

\section{Acknowledgments}

We thank the Bio Based Industries and the EU Horizon 2020 for the received fund 745839 necessary for the project research PolyBioSkin. Moreover we thank for the free samples of Chitin Nanofibril and Bio-lignin received, respectively from MAVI Sud (Italy) and CIMV (France).

\section{References}

1. World News Wipe (2017) Global Regenerative Medicine Market Analysis \& Forecast 2017-2021. Research and Market Report, Dublin, Ireland.

2. He W, Goodking D, Kowal P (2016) An Aging World: 2015. U S Census Bureau, International Population Reports, US Government Publishing Office, USA.

3. United Nations, Department of Economic and Social Affairs, Population Division (2017) World Population Ageing. USA.

4. Morganti P, Febo P (2017) Innovative Tissue Engineering for an Enlarged Market. J Clin Cosmet Dermatol 2.
5. US Department of Commerce, International trade administration, US commercial service (2016) Cosmetic \& Toiletries Market Overviews 2015. Market Research Library.

6. Gerstle T (2016) Asia Personal Care \& Cosmetics Market Guide 2016. US Department of Commerce, USA.

7. European Commission (2012) European Strategy for Key Enabling Technologies-A Bridge to Growth and Jobs (2012) COM 341 final, Belgium.

8. Braconier H, Nicoletti G, Westemore B (2014) Policy Challenges for the Next 50 years. OECD Publishing, Policy Paper, France.

9. OECD (2015) OECD Innovation strategy 2015 An Agenda for Policy Action. Paris.

10. In-Cosmetics Asia (2017) Press release. Beauty and Personal Care.

11. PWC (2015) Medical Cost Trends: Behind the Numbers 2015, USA.

12. Morganti P, Danti S, Coltelli MB (2018) Chitin and Lignin to Produce Biocompatible Tissues. Res Clin Dermatol 1: 5-10.

13. Morganti P, Hong-Duo C (2015) From the Circular economy to a Green economy. Note I. Chitin Nanofibrils as natural by-products to manage the humans and environment ecosystems. J Appl Cosmetol 33: 101-113.

14. Morganti P (2016) New a horizon in Cosmetic Dermatology. J Appl Cosmetol 34: 15-24.

15. Gustavsson J, Cederberg C, Sonesson U, van Otterdijk K, Meybeck A (2011) Global Food Losses and Food Waste-Extent causes and Prevention. FAO library, Italy.

16. Lambertini M (2015) Living Planet a Report 2014. WWF International, Switzerland.

17. West PC, Gibbs HK, Monfreda C, Wagner J, Barford CC, et al. (2010) Trading Carbon for Food: Global comparison of carbon stocks vs. crop yields on agricultural land. Proc Natl Acad Sci U S A 107: 1964519648.

18. Morganti P, Coltelli MB, Danti S, Bugnicourt E (2017) The Skin: Goal of the EU PolyBioSkin Project. Global Res J Pharm Pharmacol 2: 7-13.

19. Morganti P, Coltelli MB, Danti S (2018) Biobased Tissues for Innovative Cosmetic Products: Polybioskin as an EU Research Project. Global J Nanomed 3. 
20. Morganti $\mathrm{P}$, Palombo $\mathrm{M}$, Anniboletti T, Carezzi F, Nunziata $\mathrm{ML}$, et al. (2017) Fully-biodegradable and skin-friendly beauty masks. Personal Care Asia Pacific 18: 65-67.

21. Morganti P, Fusco A, Paoletti I, Perfetto B, Del Ciotto P, et al. (2017) Antiinflammatory, Immunomodulatory and Tissue Repair Activity on Human Keratinocytes by Green Innovative Nanocomposites. Materials (Basel) 10: 843.

22. Morganti P, Palombo M, Tischenko G, Yudin VE, Guarneri F, et al. (2014) Chitin-Hyaluronan Nanoparticles: A multifunctional carrier to deliver anti-aging ingredients through the skin. Cosmetics 1: 140158.

23. Henriksson $G$ (2017) What are the biological functions of lignin and its complexion with carbohydrates? Nor Pulp Pap Res J 32: 527-541.

24. Wiechers JW (2008) Skin Delivery: What it is and Why We Need it In: JW Wiechers (eds) Skin Delivery Systems. Allured Publishing Co, USA 1-21.

25. Iriti M, Varoni EM (2017) Moving to the Field: Plant Innate Immunity in Crop Protection. Int J Mol Sci 18: 640.

26. Patel S, Goyal A (2017) Chitin and chitinase: Role in pathogenicity, allergenicity and health. Int J Biol Macromol 97: 331-338.

27. Zhao W, Simmons B, Singh S, Ragauskas A, Cheng G (2016) From Lignin Association to Nano-/Micro-particle Preparation: Extracting a Higher Value of Lignin. Green Chemistry 18: 5693-5700.

28. Nafisi M, Fimognari L, Sakuragi Y (2015) Interplay between the cell wall and phytormones in interaction between plants and necrotrophic pathogens. Phytochemistry 112: 63-71.

29. Freeman BC, Beattie GA (2008) An Overview of Plant Defenses against Pathogens and Herbivores. The Plant Health Instructor.

30. Morganti P, Febo P, Cardillo M, Donnarumma G, Baroni A (2017) Chitin Nanofibril and Lignin: Natural Polymers of Biomedical Interest. J Clin Cosmet Dermatol 1.

31. Lee CG, Da Silva CA, Lee YJ, Hartl D, Elias JA (2008) Chitin Regulation of Immune Responses: An Old Molecule With New Roles. Curr Opinion Immunol 20: 684-689.

32. Lee CG, Da Silva CA, Dela Cruz CS, Ahangari F, Ma B, et al. (2011) Role of Chitin and Chitinase/Chitinase-Like Proteins in Inflammation,Tissue Remodelling,and Injury. Annu Rev Physiol 73: 479-501.

33. Svetoslav N, Petrov M, Lymperakis L, Friák M, Sachs C, et al. (2010) Revealing the Design Principles of High-Performance Biological Composites Using Ab initio and Multiscale Simulations: The Example of Lobster Cuticle. Adv Mater 22: 519-526.

34. Mushi NE, Utsel S, Berglund LA (2014) Nanostructured biocomposite films of high toughness based on native chitin Nanofibrils and chitosan. Front Chem 2: 99.

35. Wang B, Yao M, Longxian LV, Ling Z, Li L (2017) The Human Microbiota in Health and Disease. Engineering 3: 71-82.

36. Ashley EA (2015) The precision medicine initiative: A new national effort. JAMA 313: 2119-2120.

37. Kaptchuk TJ (2000) The Web That Has No Weaver: Understanding Chinese Medicine. $2^{\text {nd }}$ Edition, McGraw-Hill Professional, USA.

38. Yao L, Chen Y, Wang X, Shi X ,Wang Y, et al. (2017) Appraising the quality of clinical practice guidelines in traditional Chinese medicine using AGREE II instrument: A systemic review. Int J Clin Pract 71.

39. Morganti P, Chen HD, Gao XH (2016) Chitin Nanofibril: A natural ecofriendly and Immunoadjuvant active carrier for Medical use. J Appl Cosmetol 34: 141-154.
40. Pan X, Kadka JF, Ehara K, Gilkes N, Saddker JN (2006) Organosolv ethanol Lignin from hybrid poplar as a radical scavenger: Relationship between Lignin structure, extraction conditions, and antioxidant activity. J Agric Food Chem 54: 5806-5813.

41. Mezzana P (2008) Clinical Efficacy of a new chitin nanofibrils-based gel in wound healing. Acta Chir Plast 50: 81-84.

42. Tucci MG, Mattioli MB, Ricotti G, Biagini G (1999) Polysaccarides: Bealth-Environment Binomial. J Appl Cosmetol 17: 94-101.

43. Anniboletti T, Palombo M, Moroni S, Bruno A, Palombo P, et al. (2018) Clinical, activity of innovative non-woven tussues. In: P Morganti (eds) Green Bio-economy and Bio-Nanotechnology for a more sustainable Environment. MDPI Ed, Basel, Switzerland.

44. Morganti P, Palombo M, Carezzi F, Nunziata ML, Morganti G, et al. (2016) Green Nanotechnology Serving the Bio-economy: Natural Beauty Masks to save the save the Environment. Cosmetics 3: 41.

45. Morganti P, Palombo M, Fabrizi G, Guarneri F, Slovacchia F, et al. (2013) New insight on Anti-aging activity of Chitin NanofibrilHyaluronan block copolymers entrapping active ingredients: in vitro and in vivo study. J Appl Cosmetol 31: 1-29.

46. Morganti P, Fabrizi G, Guarneri F, Palombo M, Palombo P, et al. (2011) Repair Activity of Skin Barrier by Chitin-Nanofibril Complexes. SOFW-Journal 137: 19-25.

47. Anastopoulos I, Bhatnager A, Bikiaris DN, Kyzas GZ (2017) Chitin Adsorbents for Toxic Metal: A Review. Int J Mol Sci 18

48. Morganti P, Ciotto PD, Stoller M, Chianese A (2016) Antibacterial and Anti-inflammatory Green Nanocomposites. Chem Eng Trans 47: 6166.

49. Morganti P, Del Ciotto P, Carezzi F, Guarneri F, Yip Jui Yeo (2014) Skin Lightening Efficacy of New Formulations Enhanced by Chitin Nanoparticles Delivery System. Note I. J Appl Cosmetol 32: 57-71.

50. Morganti P, Fabrizi G, Ruocco E, Del Ciotto P, Palombo P, et al. (2009) Cosmetic \&Toiletries USA. 124: 66-73.

51. Morganti P, Fabrizi G, Del Ciotto P, Palombo P, Palombo M, et al. (2011) The Boosting Activity of Chitin Nanofibrils. Eurocosmetics 19: $22-26$.

52. Bell G, Mora S, Greenland P, Tsai M, Gill E, et al. (2017) Association of Air Pollution Exposures with High-Density Lipoprotein Cholestero and Particle Number. Arteriosol Thromb Vasc Biol 37: 976-982.

53. Rambiesa J, Ruzgas T, Englom J, Holefors A (2018) The Impact of Pollution on Skin and Proper Efficacy Testing for Anti-Pollution Claims. Cosmetics 5: 4

54. WHO (2016) Ambient Air Pollution: A Global Assessment of Exposure and Burden of Disease. World Health Organization, Geneve, Switzerland.

55. Pillai CKS, Sharma CP (2009) Electrospinning of Chitin and Chitosan nanofibrils. Trends Biomater. Artif. Organs 22: 179-201.

56. Porpursorkhabi V, Mohanty AK, Misra M (2014) Electrospinning of Aqueous Lignin/Poly (ethylene oxide) complexes. J Appl Polym Sci 132: 41260 .

57. Dobrovolskaia IP, Yudin VE, Popryadukhin PV, Lebedeva IO, Shabunin AS, et al. (2016) In vivo study of the nanofiber-based composite wound dressing intended for treatment of deep skin wounds. J Appl Cosmetol 34: 1-8

58. Moncunill AD, Ahrens G (2018) PolyBioskin. High Performance Functional Bio-Based Products in the Biomedical, Cosmetic, and Sanitary Sectors. Newsletter 1: 1-4. 